Izlaganje sa znanstvenog skupa

Conference paper

\title{
STANJE I GOSPODARSKE PERSPEKTIVE UZGOJA ZAGORSKOG PURANA U VARAŽDINSKOJ ŽUPANIJI
}

\author{
V. Kurečić, Z. Janječić, S. Mužic, Z. Grgić, D. Bedeković
}

\begin{abstract}
Sažetak
Puran se na širem području Hrvatskog zagorja uzgaja od 16. stoljeća. Nakon otkrića Novog svijeta vjerojatno je iz Srednje Amerike brodovima stigao u Europu, najvjerojatnije u Španjolsku, zatim u Englesku pa u Njemačku i Italiju, odakle se proširio i u naše krajeve. S vremenom se udomaćio, nije se križao s drugim pasminama pa je specifičan uzgoj u malim jatima koja su veći dio života provela na otvorenom u prirodi skupljajući hranu uvjetovao razvoj specifičnih morfoloških i fizioloških svojstava. Utjecao je na kvalitetu mesa, po čemu je zagorski puran poznat te se smatra specijalnom pasminom u gospodarskom smislu, a u uz to ima i veliko značenje kao vrijedan element biološke raznolikosti Hrvatske. U prošlosti se ova izvorna pasmina peradi slabo izučavala, tek nešto prije drugog svjetskog rata, iako je tada predstavljala značajan izvozni proizvod tradicionalnog uzgoja u zemlje zapadne Europe. Od drugog svjetskog rata do sredine devedesetih godina prošloga stoljeća zagorski puran gotovo je izumro i nestao. Svojom inicijativom i stručnošću, koncem devedesetih godina prošloga i početkom ovoga stoljeća spasili su ga pojedini entuzijasti i stručnjaci Agronomskog fakulteta u Zagrebu. Od tada se zagorski puran ozbiljnije istražuje, podupire i promovira, iako mu broj jedinki još uvijek varira na godišnjoj razini. U svakom je slučaju spašen, čak je u nekim inicijativama povremeno bio i ozbiljna robna marka kojoj, na kraju se pokazalo, treba stabilnost i kontinuitet uzgoja. Ovaj rad prikazuje stanje i gospodarske perspektive zagorskog purana u Varaždinskoj županiji.
\end{abstract}

Ključne riječi: zagorski puran, biološka raznolikost, tradicionalni uzgoj, Varaždinska županija

\section{Uvod}

Moderna peradarska proizvodnja u zatvorenim objektima sa strogo kontroliranim mikroklimatskim uvjetima i s visoko selekcioniranim hibridnim linijama purana dosegla je fantastične proizvodne rezultate te predstavlja bazu za prehrambenu industriju i praktički svakodnevnu prehranu velikog broja ljudi. Međutim, paralelno sa specijaliziranom industrijskom proizvodnjom peradi sve se više javlja svijest i potreba za proizvodima dobivenim ekstenzivnom proizvodnjom, „u prirodi“, od autohtonih odnosno izvornih pasmina peradi, čije su vrijednosti i značenje nemjerljivi i dragocjeni iz puno aspekata. Jedna od takvih pasmina peradi je i zagorski puran koji se nekoliko stotina godina uzgaja na području Hrvatskog zagorja, bez miješanja s drugim pasminama, u malim jatima koja većinu života provode u prirodi na otvorenom, što je stvorilo specifična morfološka i fiziološka svojstva te utjecalo na kvalitetu mesa (Janječić i Mužic, 2007.).

O toj „Zagorskoj“ ptici malo se istraživalo, tek nešto u prvoj polovici 20. st., da bi ga ugroženog, prorijeđenog i gotovo zaboravljenog ,iz pepela“ podigli entuzijasti pojedinci, a naročito stručnjaci Agronomskog fakulteta u Zagrebu koncem devedesetih godina prošloga i početkom ovoga novog stoljeća. Zagorski puran je „preživio“ i opstao, ali i dalje proživljava oscilacije u svom broju i korištenju.

Rad je priopćen na znanstveno stručnom simpoziju Peradarski dani, Šibenik od 13. do 16.05.2015. godine. Vladimir Kurečić, Vladimira Nazora 71, Petrijanec, Hrvatska

Prof. dr. sc. Zlatko Janječić, e-mail: zjanjecic@agr.hr, tel.: ++385 (0) 1239 3951, faks: ++385 (0) 12393932 ,

Prof. dr. sc. Stjepan Mužic, Prof. dr. sc. Zoran Grgić, doc. dr. sc. Dalibor Bedeković,

Sveučilište u Zagrebu, Agronomski fakultet, Svetošimunska 25, Zagreb, Republika Hrvatska 
Cilj rada bio je utvrditi brojčano stanje zagorskih purana koji se uzgajaju na području Varaždinske županije, broj uzgajivača, ostale podatke važne za organizaciju uzgoja te ekonomsku isplativost proizvodnje zagorskog purana na obiteljskim gospodarstvima.

\section{Materijal i metode}

Podaci su dobiveni iz vlastitog istraživanja, iz godišnjih izvještaja Hrvatske poljoprivredne agencije (HPA) te iz podataka udruga i zadruga koje se bave uzgojem zagorskog purana na području Varaždinske županije. Izvršen je obilazak uzgajivača zagorskih purana na području Varaždinske županije, pri čemu su metodom ankete prikupljeni podaci o brojčanom stanju purana, broju uzgajivača, veličini obiteljskih gospodarstava, kao i mnogi drugi podaci vezani uz sadašnjost i budućnost uzgoja. U vezi s ekonomskom isplativosti korištene su metode kalkulacije varijabilnih troškova (Grgić, 1998.).

\section{Rezultati istraživanja i rasprava}

U tablici 1. prikazan je broj uzgajivača čiji su purani u selekcijskom obuhvatu umatičeni i prstenovani u Varaždinskoj županiji od 2001. do 2013. godine (HPA, 2014.). Radi se u pravilu o obiteljskim gospodarstvima s po 9-10 kljunova, dakle $s$ dva matična jata, $s$ jednim puranom i četiri do pet purica u svakom jatu. Interes za selekcijski obuhvat od strane uzgajivača znatno varira ovisno o razini organiziranosti kroz udruge ili zadruge i o iznosu poticaja koji su od samog početka varirali u varijantama: 140/110 kn, $90 / 90 \mathrm{kn}, 150 / 110 \mathrm{kn}, 150 \mathrm{kn}$ po puranu i purici (u ovom slučaju 750 kn po jatu) službeno, ali u stvarnosti puno manje uz zakašnjelo i neizvjesno plaćanje od strane države, obveze upisivanja u upisnik i slične administrativne procedure itd.

Tablica 1. Broj uzgajivača i broj umatičenih zagorskih purana u Varaždinskoj županiji od 2001. do 2013., HPA 2014.

Table 1 Number of growers and number of registered Zagorje Turkey in Varaždin County, 2001-2013 (HPA 2014)

\begin{tabular}{lcc}
\hline Godina / Year & Broj uzgajivača / Number of growers & Broj purana / Number of turkeys \\
\hline 2001. & 51 & 490 \\
\hline 2002. & 102 & 985 \\
\hline 2003. & 65 & 543 \\
\hline 2004. & 62 & 503 \\
\hline 2005. & 51 & 486 \\
\hline 2006. & 49 & 466 \\
\hline 2007. & 45 & 343 \\
\hline 2008. & 75 & 760 \\
\hline 2009. & 103 & 904 \\
\hline 2010. & 96 & 989 \\
\hline 2011. & 101 & 905 \\
\hline 2012. & 74 & 654 \\
\hline 2013. & 59 & 528 \\
\hline
\end{tabular}


Tablica 2. daje prikaz ukupnog i prosječnog broja jaja i purića po puri u Varaždinskoj županiji od 2009. do 2013. godine (HPA, 2014.). Iako je broj nasađenih jaja bio gotovo identičan 2009. i 2013. godine broj odgojenih purića u 2013. godini bio je veći u prosjeku za 4 komada. Dobiveni se rezultati najvjerojatnije mogu pripisati boljoj izobrazbi samih uzgajivača te primjeni dobivenih spoznaja u prijmu jednodnevnih purića te uzgoju u toploj fazi.

Tablica 2. Ukupan i prosječan broj jaja i purića po puri, HPA 2014.

Table 2 Total number of eggs and poults per female turkey (HPA 2014)

\begin{tabular}{|c|c|c|c|c|c|}
\hline $\begin{array}{l}\text { Godina } \\
\text { Year }\end{array}$ & & $\begin{array}{c}\text { Snesena } \\
\text { jaja } \\
\text { Laid eggs }\end{array}$ & $\begin{array}{c}\text { Nasađena } \\
\text { jaja } \\
\text { Hatching eggs }\end{array}$ & $\begin{array}{c}\text { Izvaljano } \\
\text { purića } \\
\text { Hatched poults }\end{array}$ & $\begin{array}{c}\text { Odgojeno } \\
\text { purića } \\
\text { Alive poults }\end{array}$ \\
\hline \multirow{2}{*}{2009.} & $\begin{array}{l}\text { Ukupno } \\
\text { Total }\end{array}$ & 13903 & 12757 & 9543 & 8423 \\
\hline & $\begin{array}{l}\text { Prosječno po puri } \\
\text { Mean per female turkey }\end{array}$ & 18,39 & 16,87 & 12,62 & 11,15 \\
\hline \multirow{2}{*}{2010.} & $\begin{array}{l}\text { Ukupno } \\
\text { Total }\end{array}$ & 13457 & 12522 & 10022 & 8674 \\
\hline & $\begin{array}{l}\text { Prosječno po puri } \\
\text { Mean per female turkey }\end{array}$ & 16,72 & 15,56 & 12,45 & 10,78 \\
\hline \multirow{2}{*}{2011.} & $\begin{array}{l}\text { Ukupno } \\
\text { Total }\end{array}$ & 13559 & 13451 & 12767 & 12041 \\
\hline & $\begin{array}{l}\text { Prosječno po puri } \\
\text { Mean per female turkey }\end{array}$ & 17,84 & 17,70 & 16,80 & 15,75 \\
\hline \multirow{2}{*}{2012.} & $\begin{array}{l}\text { Ukupno } \\
\text { Total }\end{array}$ & 9514 & 8945 & 8567 & 8404 \\
\hline & $\begin{array}{l}\text { Prosječno po puri } \\
\text { Mean per female turkey }\end{array}$ & 18,90 & 18,43 & 17,58 & 17,37 \\
\hline 2013. & $\begin{array}{l}\text { Ukupno } \\
\text { Total }\end{array}$ & 9007 & 8707 & 8163 & 7889 \\
\hline
\end{tabular}

Anketom je obuhvaćeno 50 gospodarstava, većinom onih koji su u selekcijskom obuhvatu, ali i dijelom onih koji nisu. Status gospodarstva je uglavnom OPG, a prosječna dob uzgajivača na anketiranim gospodarstvima iznosi 50 godina. Velik broj uzgajivača je prošla dodatnu izobrazbu o uzgoju zagorskih purana putem koje su puno naučili i u pozitivnom smislu promijenili pristup uzgoju.

Iz provedene je ankete vidljivo da se zagorski puran uzgaja na cijelom području Varaždinske županije: od Varaždina na sjeveru do Breznice i Mirkovca na jugu, od Bednje na zapadu do Ludbrega i Hrženice na istoku, u stotinjak sela kod dvjestotinjak uzgajivača od kojih je oko 150 prošlo kroz selekcijski obuhvat. Oko 50 uzgajivača s jednim jatom nije ulazilo u obuhvat koji purane uzgajaju isključivo za sebe i svoju obitelj. Radi se često o rubnim dijelovima županije sa starijim nositeljima gospodarstva. Broj matičnih jata u domaćinstvu kreće se u rasponu od 
1 do 4 . Zbrojeno, radi se dakle o ukupno 288 rasplodnih purana i 992 pure od kojih se godišnje uzgoji oko 13.000 kljunova. Od ukupnog broja rasplodnih zagorskih purana i pura brončanom je soju pripadalo $52 \%$, sivom soju $27 \%$, crnom soju $13 \%$, a svijetlom soju $12 \%$ životinja.

Purice u prosjeku započinju s nesenjem jaja polovicom ožujka. Vrlo mali broj uzgajivača stimulira raniju nesivost i produljenje sezone nesenja produljenjem svjetlosnog dana. Prosječni broj snesenih jaja po puri u proljetnoj sezoni nesenja veći je od podataka HPA i iznosi preko 20 jaja. Broj nasađenih jaja po puri iznosi 15-19 (prosječno 17). Većina uzgajivača inkubira jaja prirodno, dok samo 5 uzgajivača inkubira u inkubatoru za sebe i iz usluge. Prosječan broj izvaljenih purića odgovara podacima HPA. Prosječna smrtnost iznosi 8\%. Oko 60\% uzgajivača preventivno cijepi purane tijekom uzgoja protiv pojave zaraznih bolesti. U posljednje vrijeme provodi se stroga sanitacija objekta kako bi se spriječila pojava i širenje bolesti. Velika većina uzgajivača u slučaju većih zdravstvenih problema konzultira se sa stručnjacima. Površina zatvorenog objekta u kojem borave purani kreće se od 20 do $40 \mathrm{~m}^{2}$. Površina ispusta za napasivanje purana tijekom tzv. hladne faze uzgoja varira od 0,5 ha do 1,5 ha. Više od $90 \%$ uzgajivača u početku purane hrane kompletnim krmnim smjesama, a kasnije kombinacijom krmne smjese, kukuruza, ječma, sojine sačme, mineralnog dodatka i hrane iz prirode (djetelina, stočni kelj i sl.).

Za prodaju su svi uzgojeni purani osim matičnog jata i osobnih potreba. Klanje purana je u preko 90\% samostalno, ,ilegalno“; tek 10 -ak \% purana klano je legalno uz veterinarski nadzor i to purani kod uzgajivača organiziranih u dvije zadruge, od kojih je jedna prestala s radom, a druga posluje reducirano. Način prodaje purana je uglavnom dogovorom osobno i narudžbom, dok je organizirana prodaja u malom postotku putem zadruga. Jednodnevni se purani prodaju po cijeni od oko $25 \mathrm{kn}$, sedmodnevni purići 30-35 kn, dok očišćena purica od 2,5-3 kg postiže cijenu od $60 \mathrm{kn} / \mathrm{kg}$, a očišćeni puran od oko $4 \mathrm{~kg}$ cijenu od $55 \mathrm{kn} / \mathrm{kg}$.

Gledajući ukupne rezultate provedene ankete vidljivo je da su uzgoj i proizvodnja zagorskog purana na području Varaždinske županije unatoč oscilacijama ustaljeni te da su razlozi oscilacija pa i povremenih stagnacija nedvojbeno i ti što i ova proizvodnja prati trenutno ekonomsko stanje u društvu (pad kupovne moći). Velika većina uzgajivača zazire od papirologije i striktnih (često kompliciranih i nepotrebnih) propisa (obnova certifikata svake godine, papirologija, upisnik, premije za matično jato koje kasne i osciliraju, obveza da se matično jato drži do 31. prosinca nakon čega ga je teško prodati itd.). Unatoč tome proizvodnja se ustalila, uzgajivači su obazovaniji i spremni učiti, a svoju proizvodnju smatraju dobrim dodatnim prihodom, iako povećanje proizvodnje - čeka neko „bolje vrijeme“.

U tablici 3. je prikazan izračun i usporedba prihoda i troškova proizvodnje na razini 2 i 4 matična jata. Bruto dohodak je kod dva jata iznosio $9.770,00 \mathrm{kn}$, a kod četiri jata $22.440,00 \mathrm{kn}$ te su svi ekonomski pokazatelji vrlo dobri u obje ispitivane veličine jata, pri čemu se u većem jatu ostvaruju bolji rezultati. To je vidljivo kroz veće vrijednosti ekonomičnosti i rentabilnosti, što u konačnici rezultira i nižom cijenom. 
Tablica 3. Izračun i usporedba prihoda i troškova proizvodnje kod 2 i 4 matična jata Table 3 Calculation and comparison of income and production costs at 2 and 4 breeding flock

\begin{tabular}{|c|c|c|}
\hline & $\begin{array}{c}2 \text { jata (8 pura x } 14 \text { purića) } \\
112 \text { purana } \\
2 \text { flock ( } 8 \text { female turkeys x } 14 \text { poults }) \\
112 \text { turkeys }\end{array}$ & $\begin{array}{c}4 \text { jata (16 pura x } 14 \text { purića) } \\
224 \text { purana } \\
4 \text { flock (16 female turkeys x } 14 \text { poults) } \\
224 \text { turkeys }\end{array}$ \\
\hline $\begin{array}{l}\text { UKUPNI PRIHOD } \\
\text { TOTAL INCOME }\end{array}$ & $24.950,00 \mathrm{kn}$ & $49.900,00 \mathrm{kn}$ \\
\hline $\begin{array}{l}\text { Uzgojeni purani } \\
\text { Grown turkeys }\end{array}$ & $\begin{array}{c}112 \times 4 \mathrm{~kg} \times 50 \mathrm{kn}= \\
22.400,00 \mathrm{kn}\end{array}$ & $\begin{array}{c}224 \times 4 \mathrm{~kg} \times 50 \mathrm{kn}= \\
44.800,00 \mathrm{kn}\end{array}$ \\
\hline $\begin{array}{l}\text { Izlučeni purani } \\
\text { Secreted turkeys }\end{array}$ & $50 \mathrm{~kg} \times 30 \mathrm{kn}=1500,00 \mathrm{kn}$ & $100 \mathrm{~kg} \times 30 \mathrm{kn}=3000,00 \mathrm{kn}$ \\
\hline $\begin{array}{l}\text { Jaja } \\
\text { Eggs }\end{array}$ & $60 \times 5 \mathrm{kn}=300,00 \mathrm{kn}$ & $120 \times 5 \mathrm{kn}=600,00 \mathrm{kn}$ \\
\hline $\begin{array}{l}\text { Poticaji } \\
\text { Government incentives }\end{array}$ & $750,00 \mathrm{kn}$ & $1.500,00 \mathrm{kn}$ \\
\hline $\begin{array}{l}\text { UKUPNI RASHOD } \\
\text { PRODUCTION COSTS }\end{array}$ & $15.180,00 \mathrm{kn}$ & $27.460,00 \mathrm{kn}$ \\
\hline $\begin{array}{l}\text { Vlastita stočna hrana } \\
\text { Own animal feed }\end{array}$ & $20 \mathrm{kn} \times 112=2.240,00 \mathrm{kn}$ & $20 \mathrm{kn} \times 224=4.480,00 \mathrm{kn}$ \\
\hline $\begin{array}{l}\text { Kupljena stočna hrana } \\
\text { Bought animal feed }\end{array}$ & $45 \mathrm{kn} \times 112=5.040,00 \mathrm{kn}$ & $45 \mathrm{kn} \times 224=10.080,00 \mathrm{kn}$ \\
\hline $\begin{array}{l}\text { Stelja } \\
\text { Bedding }\end{array}$ & $25 \mathrm{~m}^{3} \times 4 \mathrm{kn}=100,00 \mathrm{kn}$ & $50 \mathrm{~m}^{3} \times 4 \mathrm{kn}=200,00 \mathrm{kn}$ \\
\hline $\begin{array}{l}\text { Lijekovi i preventiva } \\
\text { Veterinary costs }\end{array}$ & $600,00 \mathrm{kn}$ & $1200,00 \mathrm{kn}$ \\
\hline $\begin{array}{l}\text { Energija } \\
\text { Energy }\end{array}$ & $500,00 \mathrm{kn}$ & $1000,00 \mathrm{kn}$ \\
\hline $\begin{array}{l}\text { Rad } \\
\text { Labour }\end{array}$ & $240 \mathrm{~h} \times 20 \mathrm{kn}=4.800,00 \mathrm{kn}$ & $360 \mathrm{~h} \times 20 \mathrm{kn}=7.200,00 \mathrm{kn}$ \\
\hline $\begin{array}{l}\text { Ostalo } \\
\text { Other }\end{array}$ & $500,00 \mathrm{kn}$ & $500,00 \mathrm{kn}$ \\
\hline $\begin{array}{l}\text { Usluga klanja } \\
\text { Service of slaughter }\end{array}$ & $12,5 \mathrm{kn} / \mathrm{kljun}=1.400,00 \mathrm{kn}$ & $12,5 \mathrm{kn} / \mathrm{kljun}=2.800,00 \mathrm{kn}$ \\
\hline $\begin{array}{l}\text { BRUTO DOHODAK } \\
\text { (prihodi - rashodi) } \\
\text { GROSS INCOME } \\
\text { (income - costs) }\end{array}$ & $9.770,00 \mathrm{kn}$ & $22.440,00 \mathrm{kn}$ \\
\hline $\begin{array}{l}\text { EKONOMIČNOST } \\
\text { (uk. prihodi / uk. troškovi) } \\
\text { ECONOMY } \\
\text { (tot. income / tot. costs) }\end{array}$ & 1,64 & 1,82 \\
\hline $\begin{array}{l}\text { RENTABILNOST } \\
\%=\text { dobitak / uk. troškovi } \\
\text { RENTABILITY } \\
\%=\text { gain / total costs }\end{array}$ & $64,36 \%$ & $81,72 \%$ \\
\hline $\begin{array}{l}\text { CIJENA KOŠTANJA } \\
\text { PRICE }\end{array}$ & $135,0 \mathrm{kn} /$ puran & $122,6 \mathrm{kn} /$ puran \\
\hline
\end{tabular}




\title{
Zaključak
}

Na temelju podataka dobivenih iz vlastitog istraživanja te podataka HPA možemo zaključiti da je u usporedbi s vremenom kada se zagorski puran tek počeo istraživati i kada je bio ugrožen njegov opstanak danas zagorski puran na području Varaždinske županije nije ugrožen, štoviše, uz očekivane oscilacije stabiliziran je njegov broj i uzgoj. Uzgoj zagorskih purana je dobar dodatni prihod, jer je proizvodnja zagorskog purana isplativa, uz prednost uzgoja većeg jata, jer proizvodnost, ekonomičnost i rentabilnost rastu s povećanjem broja purana u uzgoju, dok istodobno cijena pada.

\section{LITERATURA}

1. Grgić, Z. (1998): Analiza poslovanja poljoprivrednog poduzeća, Sveučilište u Zagrebu, Agronomski fakultet, interna skripta.

2. HPA (2014): Godišnje izvješće.

3. Janječić, Z., S. Mužic (2007): Phenotypic traits in Zagorje turkey. Agriculture. 13:205-208.

\section{SITUATION AND ECONOMIC PERSPECTIVES OF ZAGORJE TURKEY REARING IN VARAŽDIN COUNTY}

\begin{abstract}
Summary
Turkey has been raised as poultry across most of the Croatian region known as Hrvatsko Zagorje since the $16^{\text {th }}$ century when, after the discovery of the New World, it was brought on ships, most probably from Central America, to Europe: first to Spain, then England, Germany and Italy. Since then, it has been domesticated and has not been cross-bred with other breeds and has been specifically bred in small, free range flocks where they can naturally peck for food. This has conditioned the development of certain morphological and physiological properties and influenced the quality of meat for which Zagorje Turkey is widely renowned and considered a special breed, not only economically but also as a valuable element of Croatian biodiversity. In the past, original breeds of domestic poultry have been insufficiently researched, i.e. there were only a few attempts prior to the outbreak of World War 2, despite the fact that it represented a significant part of traditional product exports to Western Europe. From the end of World War 2 to the mid 1990s, the Zagorje Turkey almost became extinct and practically disappeared, and it took the initiative and expertise of various enthusiasts and experts from the Faculty of Agriculture of the University of Zagreb from the end 1990s and early 2000s onwards to save it. Since then, the Zagorje Turkey has been seriously researched, supported and promoted, and even though the numbers of individual turkeys saved have varied, the breed has been saved for the future. There have been occasional initiatives in which it was treated as a brand requiring stability and continuity of breeding. This paper aims to establish the situation and economic prospects of Zagorje Turkey in the County of Varaždin.
\end{abstract}

Key words: Zagorje Turkey, special breeds, biological diversity, traditional farming, Varaždin County

Primljeno: 21.12.2015.

Prihvaćeno: 04.10.2016. 